\title{
3D survey and metric analysis of the Late Roman Fort of Umm al-Dabadib (Egypt)
}

\author{
Fausta Fiorillo ${ }^{1}$, Corinna Rossi ${ }^{1}$ \\ ${ }^{1}$ Politecnico di Milano, Department ABC (Architecture, Built environment and Construction engineering), Milan, Italy.
}

\section{ABSTRACT}

This paper presents a metric analysis and interpretation of the 3D survey of the Late Roman Fort of Umm al-Dabadib (Kharga Oasis, Egypt). The aim is to verify if a modular measure was used in the construction of the Fort and whether this was congruent with Roman or Egyptian units of measurement. Horizontal and vertical sections were extracted from the 3D model of the Fort derived from a closerange photogrammetry survey method. The resulting technical drawings were used for the study and interpretation of the dimensional patterns of the Fort that revealed the correspondence of the units of measurement of the building to Egyptian Reformed Cubit. This research is part of the project LIFE (Living in a Fringe Environment), funded by the ERC CoGrant 681673.

\section{Section: RESEARCH PAPER}

Keywords: Late Roman forts; metrology; units of measurement; Egypt; photogrammetric survey

Citation: Fausta Fiorillo, Corinna Rossi, 3D survey and metric analysis of the Late Roman Fort of Umm al-Dabadib (Egypt), Acta IMEKO, vol. 7, no. 3, article 10, month year, identifier: IMEKO-ACTA-07 (2018)-03-10

Section Editor: Sabrina Grassini, Politecnico di Torino, Italy

Received April 8, 2018; In final form October 1, 2018; Published October 2018

Copyright: @ 2018 IMEKO. This is an open-access article distributed under the terms of the Creative Commons Attribution 3.0 License, which permits unrestricted use, distribution, and reproduction in any medium, provided the original author and source are credited

Funding: This work was supported by the European Research Council Consolidator Grant no. 681673.

Corresponding author: Fausta Fiorillo, fausta.fiorillo@polimi.it

\section{INTRODUCTION}

This article presents the latest results of the ongoing investigation and study of the late Roman site of Umm alDabadib, located in the Kharga Oasis, in Egypt's Western Desert. This major archaeological site lay undisturbed until recently [1,2], mainly because of its remote position and challenging environmental conditions [3].

It is characterized by the well-preserved remains of both the ancient settlement and its corresponding agricultural system, thus making it an ideal candidate for a comprehensive study encompassing both aspects [4].

The site is now the focus of a 5 -year project funded by and ERC grant, and is being studied thanks to a combination of traditional and innovative archaeological survey and 3D modelling techniques [5-7].

In particular, the adoption of 3D survey techniques allowed the creation of an accurate, metric 3D model of the entire site, that is now being used to carry out further research on these remains, including a first metrological study, that is yielding extremely interesting results, able to cast a new light on this archaeological site and on the antiquities of the Kharga Oasis.

\section{HISTORY OF THE SURVEY OF THE SITE}

Umm al-Dabadib, located at the outskirts of the Kharga Oasis (Figure 1), contains the impressive archaeological remains of a vast and well-preserved Roman installation, active in the III and IV centuries AD and abandoned at the beginning of the $\mathrm{V}$ century. The site was probably inhabited already during the Ptolemaic Period, as attested by ceramics and grave goods. The vast majority of the visible architectural remains date to the Roman Period, in particular to the IV century AD, when this site was selected to become an important element of a chain of aggressive-looking settlements, probably meant to keep under control the caravan routes that crossed the Kharga Oasis [8]. The site covers a total area of 10 square $\mathrm{km}$ and consists of three settlements (the Fortified Settlement, the Northern Settlement and the Eastern Settlement) served by an extensive agricultural system. The Northern Settlement, the oldest core of the site, consists of a group of large houses, all different from one another; the Fortified Settlement dates instead to the IV century, and consists of an extremely compact group of houses, surrounded by a continuous wall, in the middle of which rises the Fort (Figure 2). 


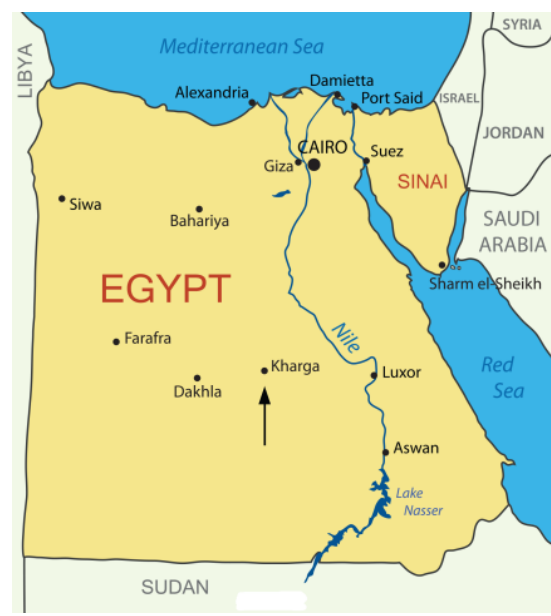

Figure 1. The Kharga Oasis, indicated by the arrow, lies $650 \mathrm{~km}$ south of Cairo and $250 \mathrm{~km}$ west of Luxor.

A first survey by theodolite in 2003 [9] of the entire archaeological site was followed by a complete photogrammetric terrestrial survey of the Fortified Settlement in 2014 [3] and 2015, with the aim to obtain a complete and accurate 3D model of this portion of the archaeological remains. This survey was prepared with extreme care as the logistic and environmental difficulties relating to the site dictated rather precise rules. The extraction and interpretation of the ensuing, accurate technical drawings offered the chance to perform a study on the unit of measurement employed in the construction of the Fort (presented here), which will be extended in the near future to the rest of the Fortified Settlement.

\section{THE 3D SURVEY OF THE FORT}

The survey was planned to ensure the minimum requirement of a 1:50 scale. It means that according to a plotting error of 0.2 $\mathrm{mm}$, the minimum Ground Sample Distance (GSD) and measurement accuracy should not exceed $10 \mathrm{~mm}$.

The Fort, located in the middle of the Fortified Settlement (Figure 2), consists of a (nearly) square building endowed with two rectangular towers on either side along the southern façade, and consists of 5 floor levels (including the ground floor, labeled 0). During the 2014 season, more than 500 photos were acquired using a Canon EOS 5D Mark III with a fix $35 \mathrm{~mm}$ lens, in order to survey the exterior of the Fort [3].

The camera network geometry corresponded to a closed circular acquisition of images taken around the external wall of the Fort. The average capture distance from the object was of about $15-20 \mathrm{~m}$ and the baseline between adjacent images was about $1,5 \mathrm{~m}$ (baseline/distance ratio of about 0,1 ). Related to the camera sensor resolution, this distance ensured a GSD of $1 \mathrm{~mm}$ for the Fort's façade and a maximum of $5 \mathrm{~mm}$ for the portion in background. The GSD is a very important parameter to establish the details that we can later measure on the output restitutions (final point cloud, orthoimages, etc.). In order to georeference the models in the same coordinate system, to scale them and to check the reconstruction accuracy, a net of GCPs (Ground Control Points) was established and measured [10]. The global accuracy of the topographic network was about $4 \mathrm{~mm}$.

The 2014 exterior survey of the Fort was integrated by the 2015 survey of the accessible internal spaces, located at level 0 and 1. It was possible to perform a complete photogrammetric survey of: (a) four rooms on the east side and (b) four rooms in

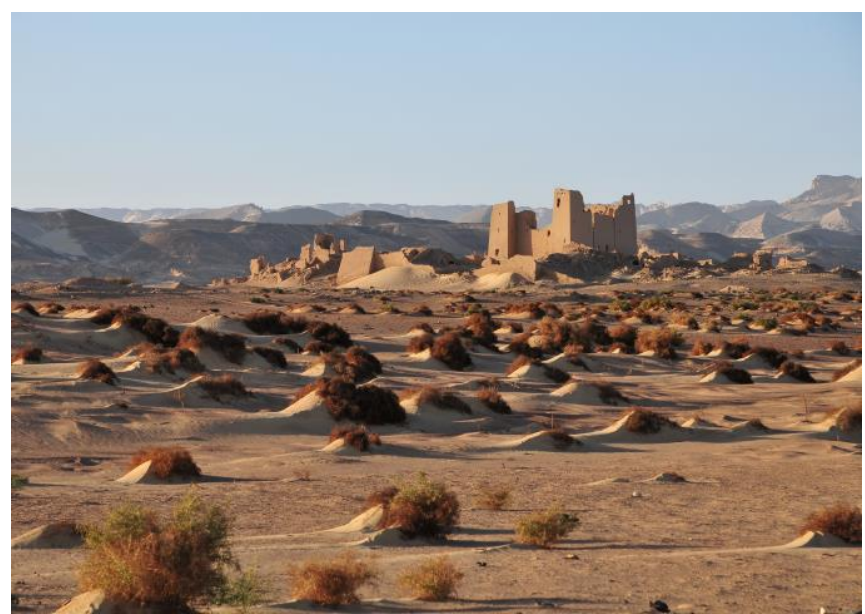

Figure 2. The Fortified Settlement with the Fort in the centre (photograph by Paolo Viviani, 2013).

the north-east corner of level 0 ; (c) two rooms on the east side of level 1; (d) the entire staircase in the south-east tower. Due to the distribution of the accessible inner rooms and the conformation of the space, the photogrammetric acquisitions were divided into the four blocks described above.

The minimum internal dimension of the rooms was about $4 \times 5 \mathrm{~m}^{2}$ with a maximum height of about $2.4 \mathrm{~m}$ and a minimum height of about $1.1 \mathrm{~m}$ (impost line of the vault). The staircase, the corridors and the passages connecting the rooms with one another are even narrower, even down to $40 \mathrm{~cm}$ only. In these critical conditions, achieving an accurate and complete dense $3 \mathrm{D}$ model which could match the exterior represented a very complex task. The lack of operating space made the use of rectilinear lenses extremely complicated. Fisheye lenses, instead, ensure a wider field of view in comparison with a rectilinear lens. This allows to simplify the survey phase and to reduce the number of photos needed for a complete 3D restitution.

For these reasons, two fisheye lenses were used: i) a Canon EOS 350D coupled with a fix $8 \mathrm{~mm}$ focal length for the level 0 and the staircase; ii) a Nikon D810 coupled with a fix $12 \mathrm{~mm}$ focal length for the level 1. During the acquisition with the fisheye optics, the team paid special attention to the base/distance ratio and to the degradation of the GSD in the boundary part of the frame [11]. Generally, a capture distance from the object of less than $1 \mathrm{~m}$ was used.

The indoor survey was designed in order to have a sufficient overlap with the external wall surface. The model of the exterior of the Fort, covered by the topographic network, was used as reference block to align the four inner block-models in the same coordinate system.

The 2014 and 2015 photogrammetric surveys were planned paying special attention to the camera network geometry [12] and to some important photogrammetric rules [13]. The photos were acquired with an average overlap between two consecutive normal views of about $80 \%$, in order to ensure the automated detection of homologous points. Convergent images were also acquired.

The acquisitions were performed using encoded markers. The markers are very important as external constrains during the image orientation and to optimize the calculation of lens distortion parameters during the self-calibration process (for details see the next section). The markers must be uniformly distributed in the area (especially where the geometry is complex) and visible in a sufficient number of photos. 


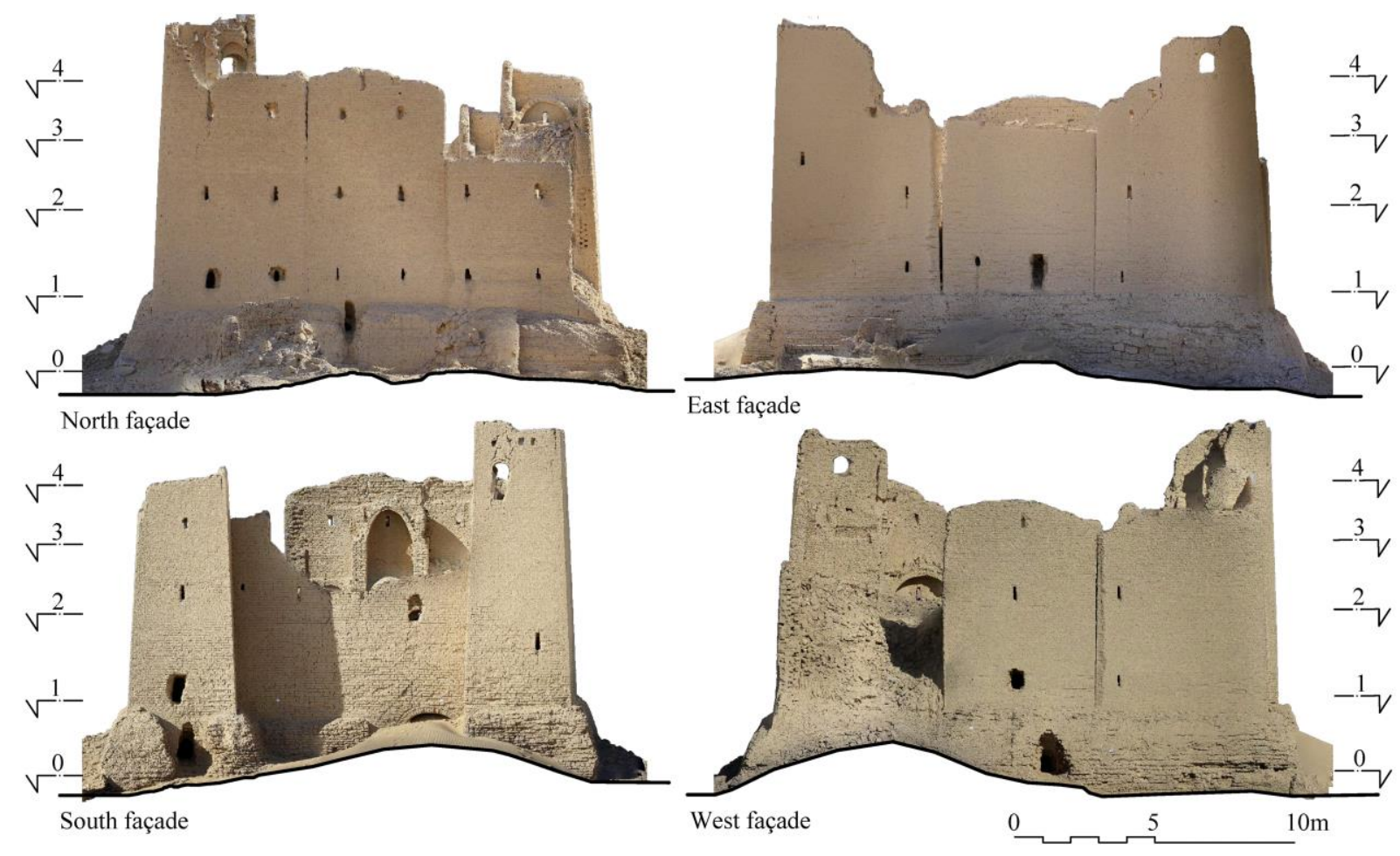

Figure 3. The orthoimages of the Fort façades showing the elevation of the horizontally-cut sections.

\section{THE PHOTOGRAMMETRIC PROCESS}

For the photogrammetric processing, we used Agisoft Photoscan, a powerful software able to successfully manage a large number of photos organized in groups of images. The first step of the photogrammetric pipeline is the automatic orientation of images, performed using the full resolution of the frame. The second step is the automatic detection of markers on the photos and the consequent optimization of the camera calibration parameters. Before the optimization, a human intervention is necessary to verify and eventually adjust the correct position of the markers on the image and/or manually add undetected markers. In the third phase, in order to scale and georeference the external model of the Fort, the coordinates acquired by total station are associated to the markers. The adoption of this work sequence avoids accidental topographical errors affecting the orientation. Instead, in order to scale the four indoor models, many reference distances among markers had to be measured, since it was not possible to perform topographic survey.

Up to this third step, each "block" of images was processed separately. In the fourth step, instead, the indoor blocks were aligned to the Fort's referenced model, using a "marker-based" method. Several couples of homologous architectural points taken on the external surface of the Fort were picked manually on the photos. We used a minimum of six markers shared by both the external and the internal survey. These markers were used as reference points to roto-translate the four indoor blocks into the reference system of the external model of the Fort.

The accuracy of the alignment of the blocks of images of the exterior of the Fort is about $3 \mathrm{~mm}$, calculated from the deviation of topographic GCPs. The accuracy of the indoor blocks (Level 0 east side, Level 0 N-E corner, Level 1 east side, Staircase) varies but keeps below $3 \mathrm{~mm}$. The general accuracy of the final model made of the aligned blocks (exterior and interior) has been established by checking the deviation of the manual marker used for the roto-translation: therefore, the final georeferencing average error has been increased to about $1 \mathrm{~cm}$.

Finally, for each oriented block of images the dense matching process was elaborated to produce a dense point cloud model and a mesh model. From the textured polygon model, it was possible to extract the orthoimages of the main façade of the Fort (Figure 3) with a maximum detail of about $2 \mathrm{~mm}$ that ensured a graphic representation to a scale 1:20 (see also Figure 4). This precision is due to the fact that the orthoimages were extracted from the 2014 survey only, which had an average GSD of $1.27 \mathrm{~mm}$ (Table 1). The possibility to visualize the four façades offered the chance to better understand the overall design of the building, to analyze its internal distribution around the central courtyard, and to reconstruct the organization into superimposing levels.

Table 1. Photogrammetric images blocks.

\begin{tabular}{lccccc}
\hline \multicolumn{1}{c}{ Images block } & Camera & Focal (mm) & Photos & Average GSD (mm) & Point cloud \\
\hline Fort exterior & Canon 5D MarkIII & 35 & 509 & 1.7 & $32,685,339$ \\
Level 0 east side & Canon 350D & 8 & 210 & 0.7 & $16,417,253$ \\
Level 0 N-E corner & Canon 350D & 8 & 208 & 0.8 & $11,862,279$ \\
Level 1 east side & Nikon D810 & 12 & 508 & 0.3 & $77,273,568$ \\
Staircase & Canon 350D & 8 & 243 & 0.6 & $12,623,173$ \\
\hline
\end{tabular}




\section{THE (RE)CONSTRUCTION OF THE MODEL}

The full photogrammetric process of the captured data allowed to obtain a series of dense point clouds and textured mesh models of the interior and exterior of the Fort that were referenced in the same coordinate system.

The unified 3D model of the building consists of more than 150 million points, with many redundant points and a variable
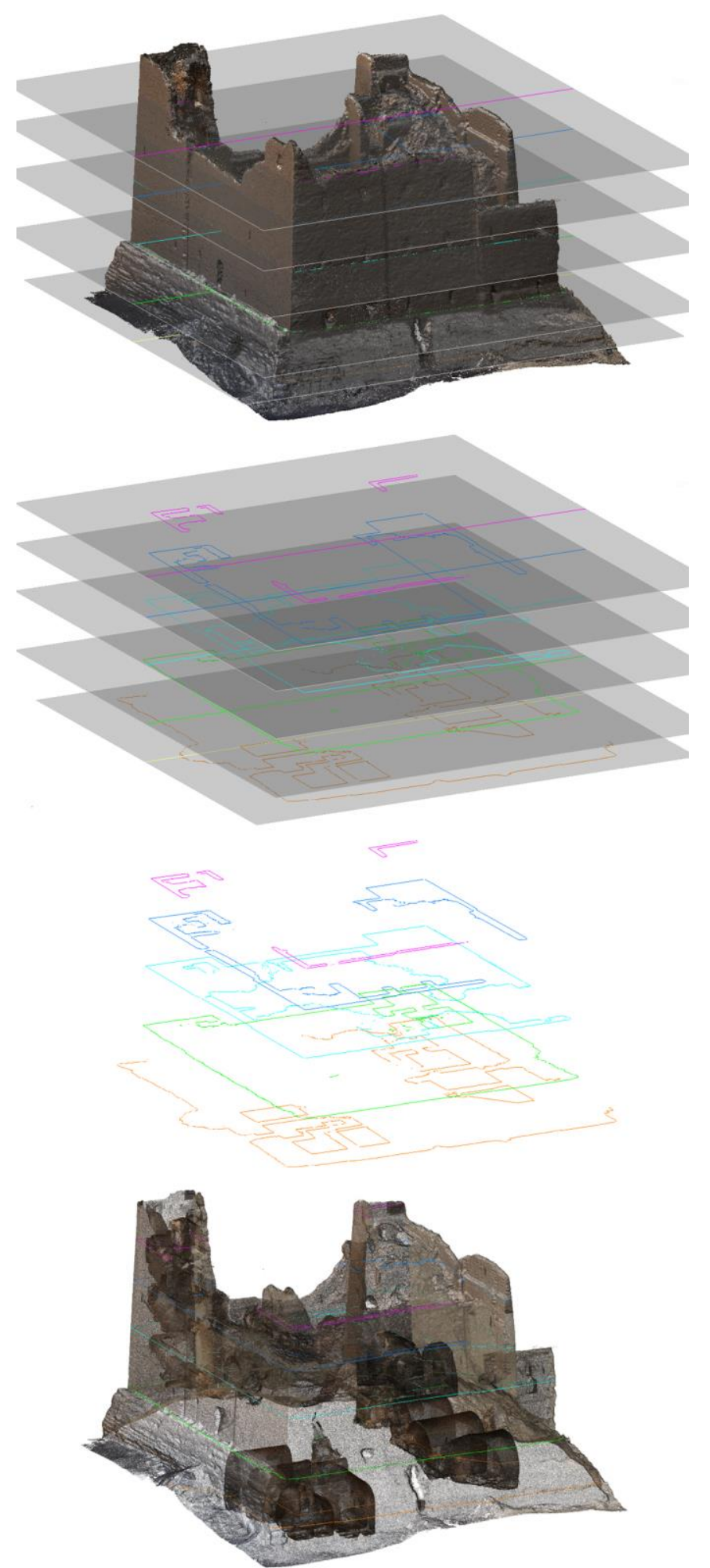

Figure 4. Horizontal sections for each floor levels, extracted from the final 3D point cloud. resolution, due to the overlapping areas among the different model-blocks, necessary to align them with one another.

In order to homogenize the resolution of the point model and in order to make it more manageable for the successive elaborations, it was subsampled with a minimum point-to-point step of $5 \mathrm{~mm}$. Therefore, it was possible to reduce the final point cloud to 37.041 .824 points. This operation was useful for the next step: the extraction of the horizontal sections. In fact, using a more uniform and homogenous point cloud, the algorithm of interpolation of the polyline from the point section works better. The final point cloud, obtained in this way, was imported in Autocad to extract horizontal sections for each floor level. In Figure 4 it is possible to see the five planes on the point cloud model and the extracted horizontal sections. The height of the section plan has always been set below the vault's impost line in order to have a correct representation and measurement of the internal spaces (clearly visible in the upper part of the transparent frontal view in Figure 5). In order to ensure the adequate density of points for the extraction of the polyline, the vertical thickness of the slices of point cloud was set equal to $1 \mathrm{~cm}$ : double of the point-to-point spatial resolution.
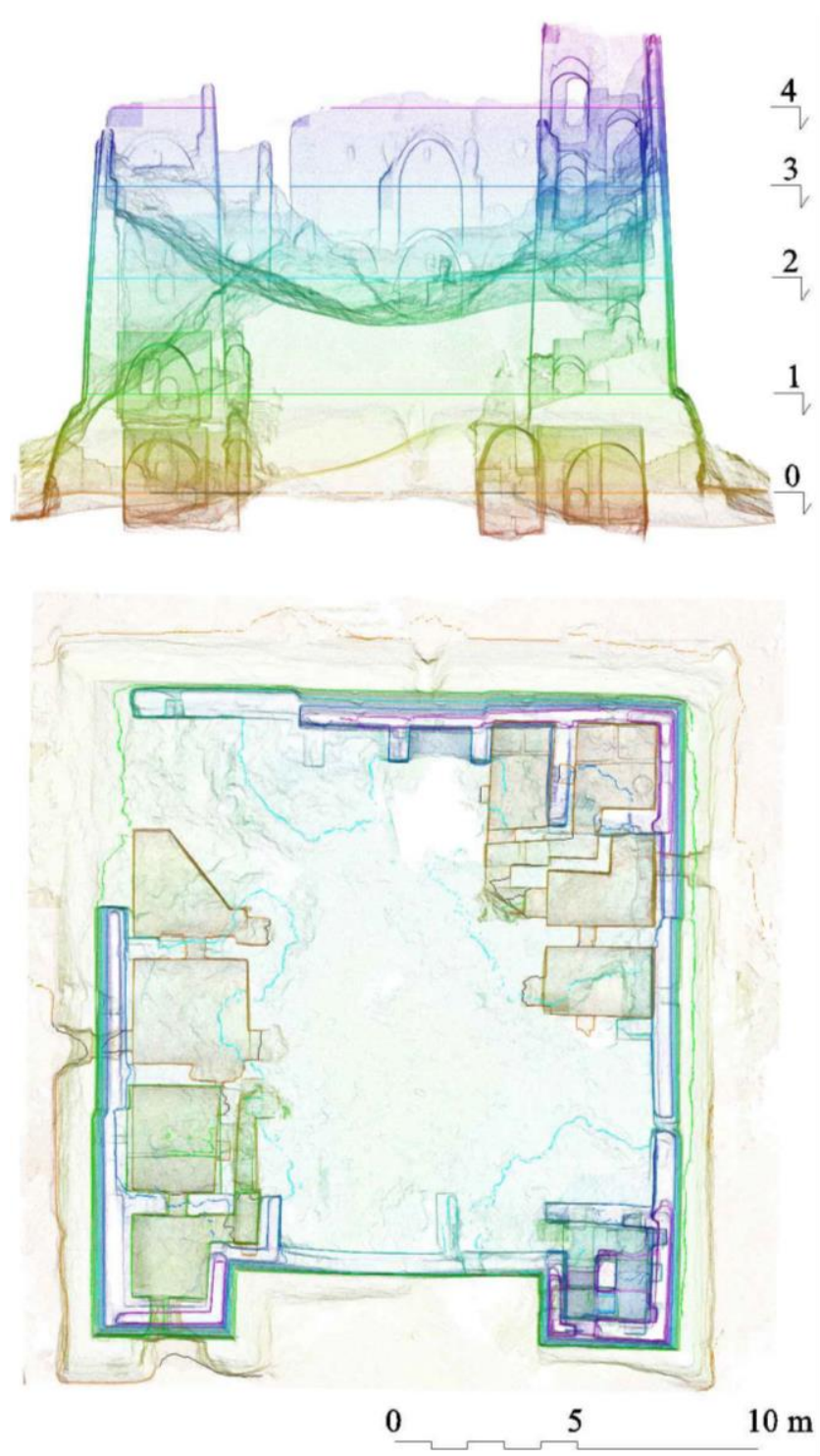

Figure 5. From above: transparent south façade with the cut section levels and top view of the different levels. 
In this way we obtained a comprehensive 3D model of the entire building, from which we could extract plans at all levels, as well as meaningful sections cut across specific points or areas (Figures 4, 5 and 6). The three-dimensional study of the building allowed the detection of irregularities and misalignments that had not been previously noted: not all rooms belonging to the same level, for instance, share the same floor level, and the same happens to the vaults, that sometimes reach different heights. This means that the internal design of the building was influenced by several factors, including probably the original ground level, that was only partly flattened before the construction began.

The ground floor is the best-documented level, as it can be entered (and thus surveyed) from various sides, and yet many important details on the internal arrangement of the building are uncertain, including the precise dimensions of the internal courtyard. The first floor can be partly reconstructed from the accessible remains, and partly by projecting the alignment of the upper and lower rooms. The remains of the third and fourth levels stick out of the collapsed mass of debris, so that they can be reconstructed up to a certain point: the precise design and extent of the central courtyard remains obscure.

All floors were served by the elaborated staircase that occupied the south-eastern tower; four flights of stairs, covered by a sequence of small vaults, revolved around a central pillar and continued to the roof level (see Figure 6). Even if the staircase is half-filled with sand, the $3 \mathrm{D}$ model of its internal space is extremely useful to reconstruct the original floor levels. The only portion that is currently inaccessible is the ground floor, totally engulfed by sand.

The vertical sections of the building show very well the marked slant of the external surface of the outer wall, in stark contrast with the vertical alignment of its internal face and of all the internal walls (see Figure 6).
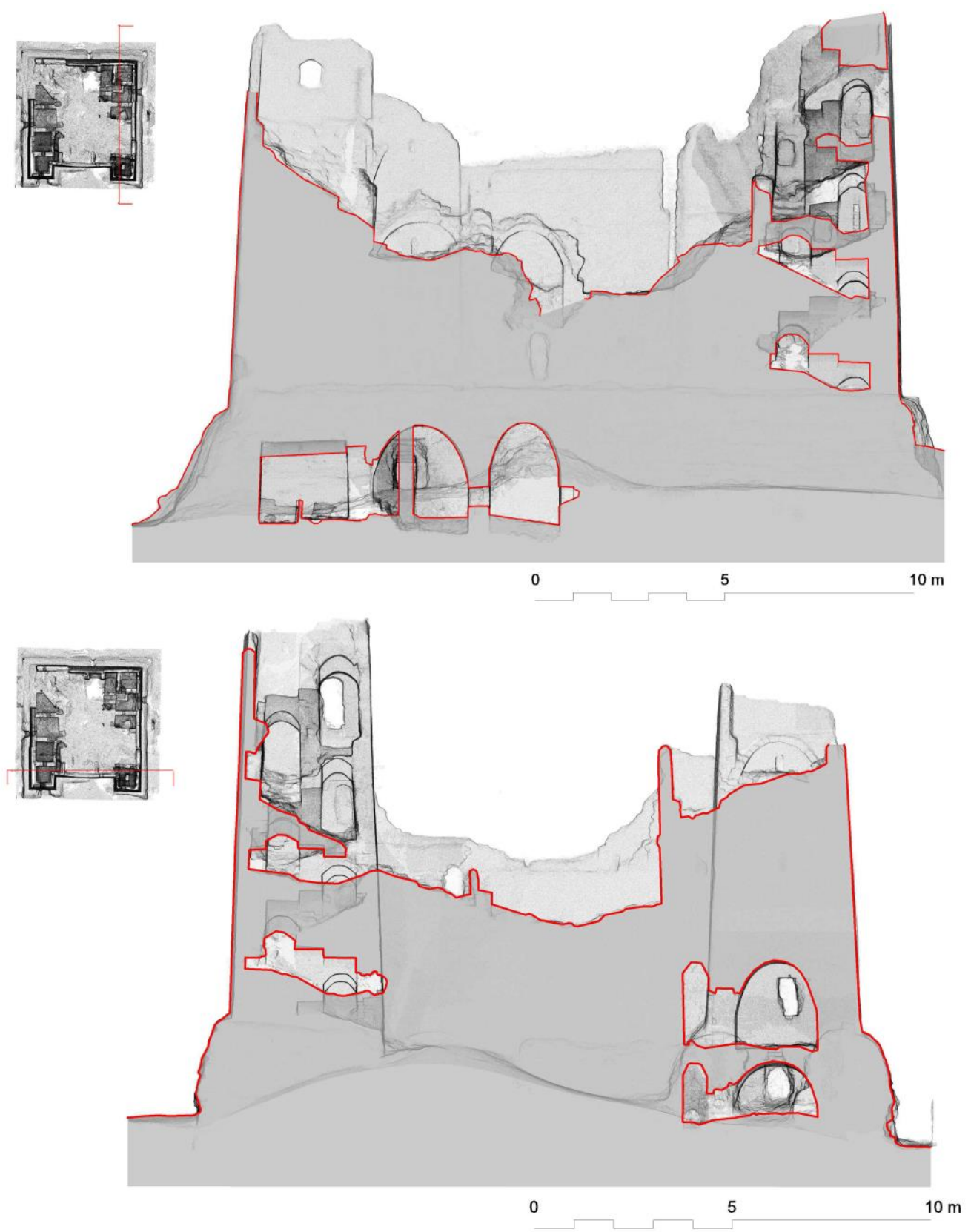

Figure 6. North-south and east-west sections of the Fort across the staircase. 


\section{THE METRIC ANALYSIS OF THE FORT}

The search for a possible unit of measurement started from the analysis of the mudbrick building technique employed for the entire settlement. The most common brickwork type (at Umm al-Dabadib, as well as at all the contemporary sites in northern Kharga) is the two headers + one stretcher wall with a thickness of about $52-53 \mathrm{~cm}$. In fact, the bricks have average dimensions of $34-36 \mathrm{~cm} \times 16-18 \mathrm{~cm} \times 8-10 \mathrm{~cm} \mathrm{[2].}$

This metric information was tested on different portions of the 3D model of the building. Figure 7, for instance, shows a detail of the orthoimage of the south façade (picked up on the internal face of the northern wall), where it is possible to see the measures of the brick and the two headers + one stretcher brickwork type.

This metric module of $52-53 \mathrm{~cm}$ does not seem to match the basic unit of Roman linear measurement which was the pes (the foot, about $29 \mathrm{~cm}$ ): instead, it corresponds exactly to the Egyptian Royal Cubit (here abbreviated as c) [14, 15]. In order to verify whether this module can be also detected in the dimensions of rooms and walls, a reference grid of $52 \mathrm{~cm}$ was mapped on the floor sections (Figure 8).

A grid based on the unit of measurement does not necessarily reflect a grid actually used by the builders; it rather represents a graphic tool to easily visualise the presence of that unit of measurement. In this case, for instance, it immediately showed that the width of the rooms at level 0 corresponds to 5.5 or $6 \mathrm{c}$; that of the central court probably to $13.5 \mathrm{c}$; that the east tower measured $3.5 \mathrm{c} \times 4.5 \mathrm{c}$, and the west tower $3 \mathrm{c} \times 4 \mathrm{c}$ (Figure 9). A detailed metrological analysis, including a discussion on the units of measurement employed, will appear elsewhere [16, 17].

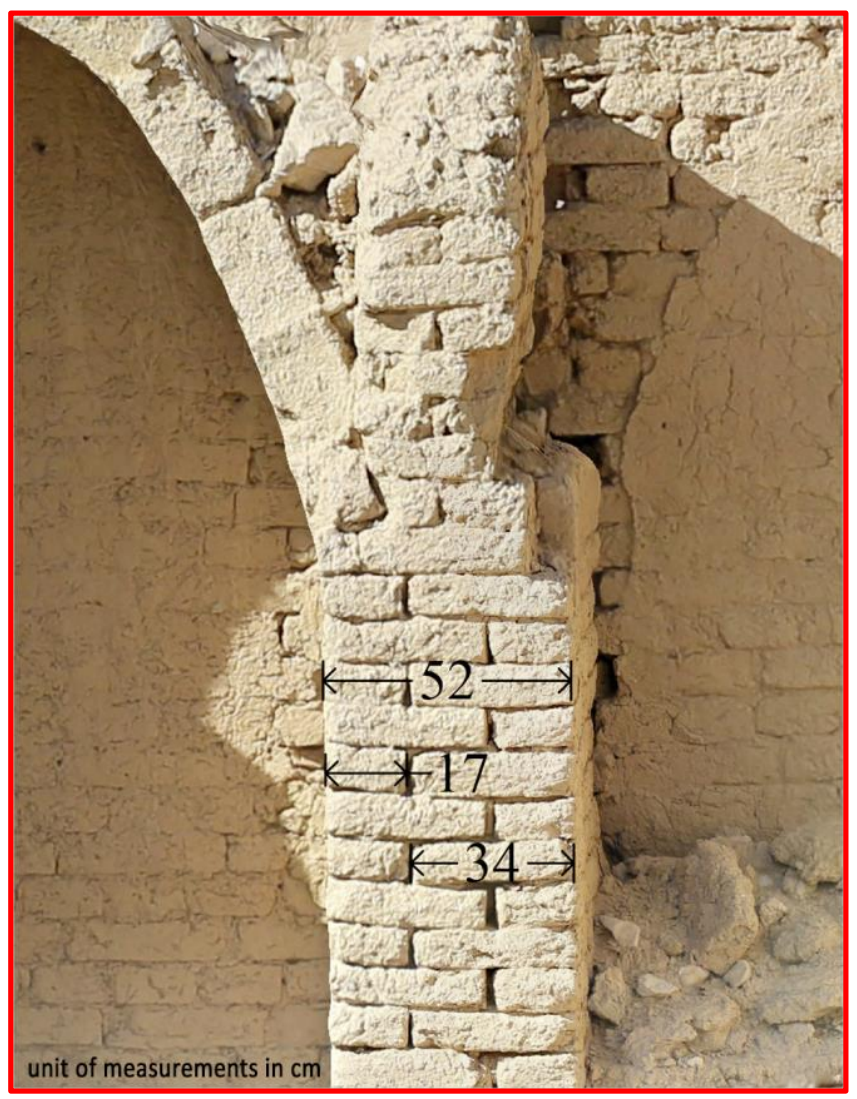

Figure 7. Detail of the orthoimage on Figure 3: it is possible to visualize the measures of the bricks (in $\mathrm{cm}$ ) and the two-header brickwork type.

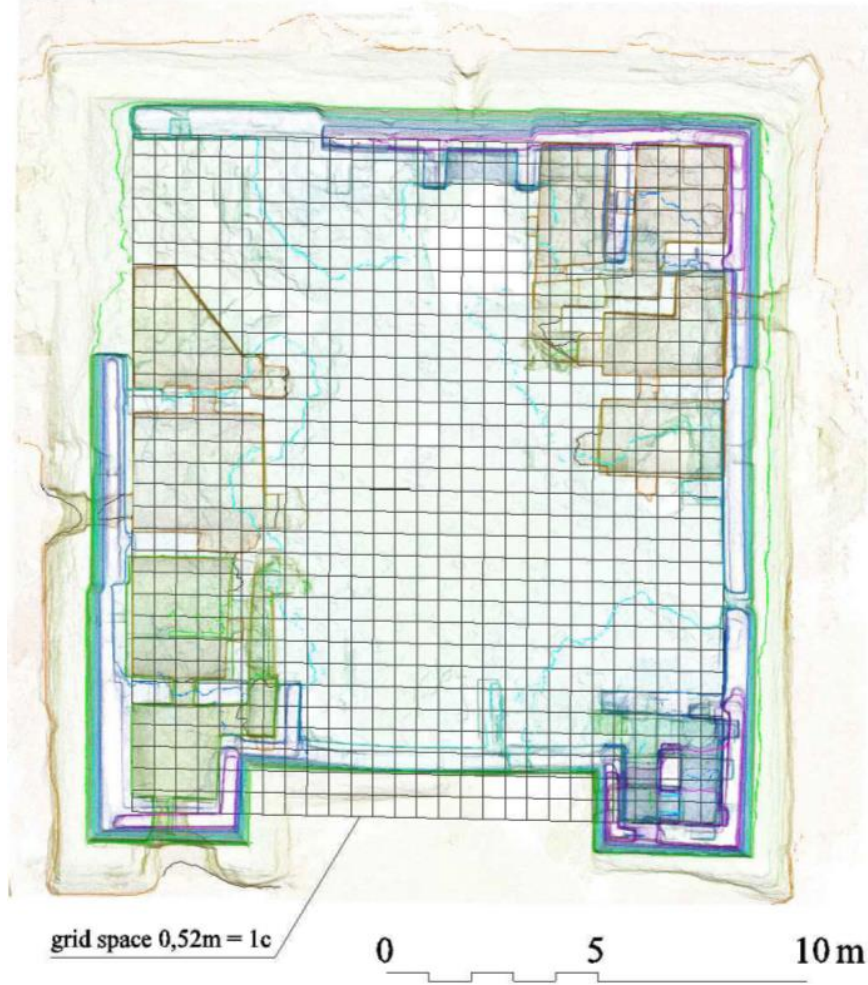

Figure 8. The Royal Cubit grid overlapped on the top view.

The level of accuracy in the dimensions of the masonry is relatively high (Figure 7), considering that looking for extreme precision makes little sense in a building made of plastered mudbrick walls.

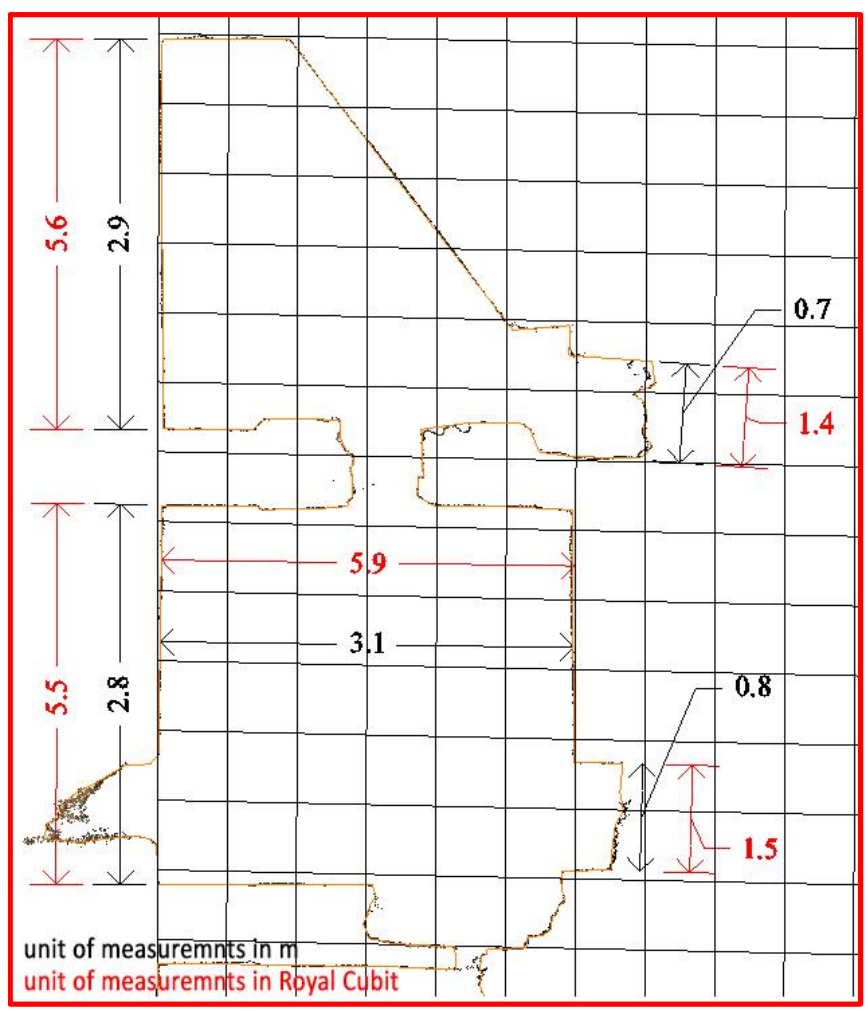

Figure 9. A detail of Figure 5 relating to level 0 : in red the dimension of the rooms in Royal Cubit unit and in black the corresponding in meters. 


\section{CONCLUSIONS}

The results of the metric analysis offered an important insight into the interpretation of the historical data. First of all, it is important to note that this is, so far, the latest attestation of the use of the ancient Egyptian unit of measurement in architecture. The use of the Royal Cubit in this Late Roman Period fortified site suggests several directions for future research: first of all, Umm al-Dabadib is one element of a chain of Late Roman fortified sites that punctuate the Kharga Oasis, and the same conclusions might therefore apply to the other sites as well.

Moreover, the use of the Royal Cubit in a Late Roman fortified installation (or chain of installations) in the middle of the Western Desert suggests that this building programme was the result of a strategic project evidently funded by the Roman authorities, but deeply rooted in the local building techniques [18].

The Umm al-Dabadib settlement is an interesting case study to analyse the Late Roman strategy to control and manage the southern border of the empire. The interpretation of the archaeological remains based on an Egyptian or Roman unit of measurement aims at understanding the history of this wellpreserved site and offers important clues for the interpretation of other similar but less-preserved sites. In addition, the presence of modular measurements may facilitate the graphic restitution of the current state of the remains, and the representation of constructive hypotheses, as basic and repetitive elements (vaults, arcs, etc.) might have been designed according to the module.

Our future aim is to extend the metric analysis presented here to the rest of the Fortified Settlement, in order to study how the same unit of measurement was employed in the construction of the other buildings.

In conclusion, although traditional, two-dimensional surveys of buildings can be extremely precise, the advantage of carrying out a metrological analysis on a metric 3D model is quite evident. It is hoped that the adoption of this survey technique will increase in the near future, in order to open the way to further analyses of this type.

\section{ACKNOWLEDGEMENT}

We wish to thank thank Francesco Fassi and Cristiana Achille for many fruitful discussions; the Egyptian Ministry of the Antiquities for their support; in particular, the former General Manager of the Antiquities of the Kharga Oasis, Mr Ahmed Ibrahim Bahgat, and the current General Manager Mohamed Ibrahim Ahmed, for their constant encouragement and support. This paper presents the results of the research currently carried out by the project LIFE (Living in a Fringe Environment), funded by the ERC CoGrant 681673.

\section{REFERENCES}

[1] C. Rossi, Umm el-Dabadib, Roman Settlement in the Kharga Oasis: Description of the Visible Remains. With a Note on 'Ayn Amur, Mitteilungen des Deutschen Archäologischen Instituts Kairo 56 (2000), pp. 235-52.

[2] C. Rossi, S. Ikram, North Kharga Oasis Survey. Explorations in Egypt's Western Desert, British Museum Publications on Egypt and Sudan 5, Peeters, Leuven, 2018, ISBN 978-90-429-3621-8.
[3] F. Fassi, C. Rossi, A. Mandelli, Emergency Survey of Endangered or Logistically Complex Archaeological Sites, Int. Arch. Photogramm. Remote Sens. Spatial Inf. Sci., XL-5/W4 (2015), pp. 85-91.

[4] C. Rossi, A. Migliozzi, F. Fassi, A. Mandelli, G. B. Chirico, C. Achille, S. Mazzoleni, Archeologia, scienza e tecnologia: lo studio del sito tardo-Romano di Umm al-Dabadib (Oasi di Kharga, Egitto), Proceedings of the seminar L.O.S.A.I. (Laboratori Open su Scienza, Arte e Innovazione) 2015, ISBN 9788899130206, pp. 221-8.

[5] F. Remondino, Heritage recording and 3D modeling with photogrammetry and 3D scanning, Remote Sensing, 3.6 (2011), pp. 1104-1138.

[6] S. Gonizzi Barsanti, F. Remondino, D. Visintini, 3D surveying and modeling of archaeological sites - some critical issues, Ann. Photogramm. Remote Sens. Spatial Inf. Sci. II-5/W1 (2013), pp. 145-150.

[7] C. Rossi, Italian Mission to Umm al-Dabadib, Season 2014 Preliminary Report, Mitteilungen-Deutschen Archaologischen Instituts Abteilung Kairo, 72 (2016), pp. 153-72.

[8] C. Rossi, Controlling the borders of the empire: the distribution of Late-Roman 'forts' in the Kharga oasis, in: R. Bagnall, P. Davoli, C. Hope (eds.), The Oasis Papers 6, Proceedings of the Sixth Conference of the Dakhla Oasis Project, Dakhla Oasis Project Monograph 15, Oxford: Oxbow, 2013, pp. 331-6.

[9] C. Rossi, S. Ikram, North Kharga Oasis Survey 2003. Preliminary Report: Umm el-Dabadib, Mitteilungen des Deutschen Archaologischen Instituts Abteilung Kairo, 62 (2006), pp. 279.

[10] F. Fassi, 3D Modeling of Complex Architecture Integrating Different Techniques - a critical overview, Int. Arch. Photogramm. Remote Sens. Spatial Inf. Sci., XXXVI-5/W47 (2007), pp. 1-11.

[11] L. Perfetti, C. Polari, F. Fassi, Fisheye Photogrammetry: Tests and Methodologies for the Survey of Narrow Spaces, Int. Arch. Photogramm. Remote Sens. Spatial Inf. Sci., XLII-2/W3 (2017), pp. 573-580.

[12] E. Nocerino, F. Menna, F. Remondino, Accuracy of Typical Photogrammetric Networks in Cultural Heritage 3D Modeling Projects, Int. Arch. Photogramm. Remote Sens. Spatial Inf. Sci., XL-5 (2014), pp. 465-472.

[13] F. Remondino, E. Nocerino, I. Toschi, F. Menna, A Critical Review of Automated Photogrammetric Processing of Large Datasets, Int. Arch. Photogramm. Remote Sens. Spatial Inf. Sci. XLII-2/W5 (2017), pp. 591-599.

[14] T. Pommerening, Weights and Measures, Pharaonic Egypt, in: R. S. Bagnall, K. Brodersen, C. B. Champion, A. Erskine and S. R. Huebner (eds.), The Encyclopedia of Ancient History. Blackwell, Oxford, 2013, pp. 7087-7092.

[15] A. P. Hirsch, Ancient Egyptian Cubits - Origin and Evolution. PhD Dissertation, University of Toronto, 2013, unpublished.

[16] F. Fiorillo, C. Rossi, Metric analysis and interpretation of the unit of measurement in the Late Roman Fort of Umm al-Dabadib (Egypt), in: MetroArchaeo 2017, pp. 139-144, ISBN 9789299008409. 3rd IMEKO International Conference on Metrology for Archaeology and Cultural Heritage, Lecce 23-25 ottobre 2017.

[17] C. Rossi, F. Fiorillo, "A metrological study of the Late Roman Fort of Umm al-Dabadib, Kharga Oasis (Egypt)", Nexus Network Journal "Architecture and Mathematics", 20, 2, (2018), pp. 373 391.

[18] C. Rossi, "Searching for the right words: what happened in Kharga in the IV century AD?", Proceedings of the colloquium Marges et frontières occidentales de l'Égypte (Cairo, 2-3 December 2017), Bibliothèque d'Étude series, in-press. 